Article

\title{
Information Application of the Regional Development: Strategic Couplings in Global Production Networks in Jiangsu, China
}

\author{
Haiying Xu ${ }^{1}\left(\right.$, Wei-Ling Hsu ${ }^{1} *{ }^{\mathbb{D}}$, Yee-Chaur Lee ${ }^{2}$, Tian-Yow Chern ${ }^{2}$ and Shr-Wei Luo ${ }^{2}$ \\ 1 School of Urban and Environmental Science, Huaiyin Normal University, Huai'an 223300, China; \\ sqxhy@126.com \\ 2 School of Architecture and Design, Chung Hua University, Hsinchu city 30012, Taiwan; \\ joeychuc@yahoo.com.tw (Y.-C.L.); cty@chu.edu.tw (T.-Y.C.); yulau0626@yahoo.com.tw (S.-W.L.) \\ * Correspondence: 8201811011@hytc.edu.cn; Tel.: +86-157-5138-5380
}

Received: 30 July 2020; Accepted: 29 August 2020; Published: 31 August 2020

\begin{abstract}
The recent literature concerning globalizing regional development has placed significant emphasis on the Global Production Network (GPN 2.0). GPN 2.0 in economic geography emphasizes that regional growth is caused by a shift in the strategic coupling mode from a low to high level. In addition, GPN 2.0 regards firm-level value capture trajectories as key analytical object, rather than the interactive relationships among scalar and divergent actors in GPN 1.0. To provide a better understanding of causal linkages between the GPNs and uneven regional development in the background of globalization and to test the applicability of GPN 2.0 analysis framework, the paper analyzed 62 Korean-invested automotive firms in Jiangsu Province, China. In order to explore the value capture trajectories of lead firms in the GPNs, the authors applied K-means clustering method to quantitatively analyze the local supply networks of lead firms from organizational and spatial dimensions. Then, comparisons were made between strategic coupling modes of GPNs and regional development in North and South Jiangsu. This study found obvious similarities within these two regions but obvious differences between them in terms of value capture trajectories. We observed that North Jiangsu is currently in the stage of "structural coupling", whereas South Jiangsu is in the stage of "functional coupling." Thus, this article argues that spatial settings such as regional assets and autonomy are key factors influencing uneven economic development. This research may provide a crucial reference for the regional development of Jiangsu, China.
\end{abstract}

Keywords: regional development; global production network 2.0; strategic coupling; K-means clustering

\section{Introduction}

Since the early 1990s, economic activity dominated by transnational corporations (TNCs) has become more fragmented and spatially dispersed on a global scale; this phenomenon is associated with economic globalization. At the United Nations Conference on Trade and Development (UNCTAD) in $2013,80 \%$ of international trade was estimated to be organized through global production networks (GPNs) [1]. A reconfiguration of the GPNs through locational shifts of value-added activities will change the spatial structure of the world economy and further affect regional development of host countries [1]. In academic research in multiple fields-including economic geography, industrial economics, and regional development-the GPNs have been the focus of discussions among scholars.

The concept of GPNs was first introduced by Manchester scholars and their collaborators. A GPN is a key analytical framework for explaining "globalizing" regional development [2-4]. The GPN framework contributes to the exploration of "strategic coupling" within the GPNs. "Strategic coupling" 
is the interactive process between TNCs and the actors of host regions or localities in unique institutional and cultural environments, and the GPN scholars believe that the realization of strategic coupling will inevitably bring about positive regional development [5].

However, the GPN framework has been criticized by many scholars. Sunley [6] argues that the most substantial problems are the lack of accuracy and issue orientation. Against this backdrop, Coe and Yueng [1,7] put forward the GPN 2.0 analysis framework in 2015. The original GPN framework has since been referred to as GPN 1.0. There are obvious differences between GPN 1.0 and GPN 2.0 in two aspects. The one is the different explanation in causal linkages between GPNs and uneven territorial development. Unlike GPN 1.0, GPN 2.0 considers that strategic couplings are dynamic processes, and to realize the strategic coupling from a low level to a high level can bring out positive regional development outcomes. Another difference between GPN 1.0 and GPN 2.0 is in the analysis schema. In GPN 2.0, capitalist dynamics are envisioned to drive firm strategies, lead to various value capture trajectories, and ultimately create economic development outcomes. However, GPN scholars still argue that there are methodological constraints in GPN 2.0 analytical framework. Yeung (2016) holds that the specific setup of GPN 2.0 still demands multi-scalar validity and reliability of the data in the specific industry to make empirical analysis [8].

The most important objective of our work is to fill the deficiency in the aspect of empirical analysis to test the operability of GPN 2.0. In this article, Jiangsu, China, is selected as the case study area, and Korean-invested automobile firms (KIAFs) are adopted as study objects, primarily because of the following considerations: First, spatial inequality in economic development can be observed within Jiangsu, and uneven economic development of FDI has been deemed a key cause of such variation [8,9]. Second, North Jiangsu is an underdeveloped region; within this region, Yancheng City is a gathering area of KIAFs. By contrast, South Jiangsu is a developed region; in South Jiangsu, Suzhou City and Wuxi City also have high concentrations of KIAFs. Thus, these case selections are suitable for comparing North and South Jiangsu. The sub-objective of this article is to formulate differentiated regional development strategies, especially with respect to the sustainable economic development of late-coming regions in the context of globalization.

The remainder of this paper is presented in five sections. Section 2 provides relevant theoretical background for comparison between GPN 1.0 and GPN 2.0 to find a suitable theoretical framework for the subsequent empirical study. Section 3 introduces the research setting, details the uneven economic development in Jiangsu, China, and examines the various developmental trajectories of North and South Jiangsu. Section 4 describes empirical analysis of the firm-level capture trajectories of KIAFs in Jiangsu. Based on the empirical results, Section 5 compares North and South Jiangsu to determine the strategic coupling stages that both subregions are in. Finally, Section 6 provides conclusions and implications.

\section{Theoretical Issues and Research Framework}

\subsection{Consideration of the Causal Mechanism of GPNs and Regional Economic Development}

The theoretical GPN framework attempts to explain some problems related to uneven regional development in the context of globalization. The aforementioned Manchester scholars have long been employed to study TNCs and foreign directed investment (FDI); they have found that not all overseas investment by TNCs is driven by narrow cost considerations, and host regions vary in their ability to 'hold down' TNCs [10]. Thus, a framework has been developed to explore relationships between TNCs and host regions. Coe et al. [11] defined the GPN framework as follows: "GPN analysis combines insights gained from GCC (global commodity chain)/GVC analysis, and aims to reveal the multi-actor and multi-scalar characteristics of transnational production systems through intersecting notions of power, value and embeddedness. In particular, attempts are made to connect with understanding of sub-national regional development and clustering dynamics." This definition highlights the multidisciplinary theoretical origins of the GPN framework. Crucially, the framework 
provides geographical perspectives of the global economy. In particular, GPN scholars draw on the concept of 'strategic coupling' in GPNs to understand globalizing regional development.

GPN 1.0 and 2.0 have obvious differences in terms of explaining the causal linkages between GPNs and regional development. In GPN 1.0, once local manufacturers have become embedded in GPNs, strategic coupling has been realized, and this realization necessarily leads to positive output in terms of regional economic development. In GPN 2.0, strategic coupling may yield positive and negative economic outputs. Alongside the increase in regional development, regional advantages continue to increase, and the coupling mode turns toward a direction more beneficial to the region [12]. Thus, strategic coupling is not a concept of static equilibrium, nor can it be completed automatically. It is a sequential process of coupling, decoupling, and recoupling [13]. During the dynamic changing process of strategic coupling, the modes and types change accordingly. Coupling modes can be divided into three types: endogenous coupling, functional coupling, and structural coupling. Endogenous coupling refers to coupling from the inside to the outside; regional actors reach outside of their regions to build GPNs and drive regional economic development, thereby yielding high captured value and autonomy. Functional coupling refers to regional actors actively satisfying the extensive demands of GPNs through the inside-to-outside and outside-to-inside development modes, thereby achieving captured value and autonomy to some extent. Structural coupling operates from the outside to the inside, that is, external actors connect the region into GPNs. Thus, structural coupling is characterized by dependency. Therefore, regional development is not the inevitable outcome of the realization of strategic coupling; by contrast, underdeveloped regions must reject low-level strategic coupling and strive for high-level coupling to achieve positive development of regional economies. Neilson (2019) [14] demonstrates that lead firms in GPNs have different local integrative strategies in different value stages. In the early stage, the lead firms tend to have few local linkages due to lack of competence locally, but in late stages the lead firms increase the local linkages. Thus, regional development policies should be sensitive to specific value stages of lead firms within GPNs. The unceasing shifting of strategic coupling modes informs policy makers and participants that because no panacea or an all-inclusive policy instrument exists, a dynamic view of regional development should be taken to facilitate the selection of a suitable regional development mode [15]. Because of the risk of regional development being locked at the low end of the value chain, regional actors should continue to seek new opportunities for upgrading regional industries to prepare themselves for modes better able to capture value.

Regarding GPN 2.0, perspectives regarding dynamic strategic coupling and the concepts of strategic coupling types have received positive responses from some scholars. Yueng, a key contributor of GPN 2.0, analyzed the development situations of typical emerging industries in South Korea, Taiwan, and Singapore based on the theories and concepts of GPN 2.0 and strategic coupling and investigated substantial changes in economic development and government-firm relationships in East Asia [16]. Grunsven and Hutchinson [17] adopted the "coupling-decoupling-recoupling" analysis framework to explain uncertainty in the development trajectories of the electronics industry in Johor, Malaysia. Cinta and Salvador [18] employed the concepts of strategic coupling and upgrading in GPN 2.0 to explain the key role played by the cross-regional network in improving local firms' innovation abilities; the researchers divided the strategic coupling process into cooperation, mediation, self-interestedness, and capture and analyzed the shaping process of tourist destinations' evolutionary paths by using cross-regional networks. He [19] employed the coupling-decoupling-recoupling framework in GPNs to analyze the coupling characteristics of East China and offered policy-oriented suggestions for the redevelopment in East China. Neilson et al (2020) [20] makes empirical analysis on strategic coupling in the Indonesia Coco sector, arguing that Industry outcomes are strongly influenced by Indonesia's position within a set of globally-connected networks and the alignment of national policy with the particular strategies of lead firms within these networks in a process of strategic coupling. The aforementioned scholars have argued that the method of considering dynamic strategic coupling has theoretical superiority in terms of explaining the dynamic aspects of regional economic development in the context of globalization. 


\subsection{Consideration of the GPN 2.0 Analysis Framework}

The GPN 2.0 analysis framework indicates that a positive output for regional development can be achieved only through the substitution of low-level coupling with high-level strategic coupling; thus, at the level of empirical analysis, how analyses should be conducted to clarify the current strategic coupling modes warrants investigation. The GPN 2.0 analysis framework shows many differences with GPN 1.0 (see Figure 1). It holds that the regional development is economic development process on ground, that is, the territoriality of GPN. The territoriality of GPNs manifests as the developmental output of spatial and organizational connections with GPNs, which unfold primarily along two dimensions: vertical and horizontal. The vertical dimension is the organizational dimension of GPNs and serves as the global-local connection. The horizontal dimension is the spatial dimension, which is the touch-down of the global-local connection, also known as territorial embeddedness. GPN 2.0 emphasizes that the cross-influence of the horizontal and vertical driving forces is the driving mechanism of the strategic coupling process of GPNs and regional development. Therefore, in analysis of regional economic development requires by GPN 2.0, both network relations and spatial relations should be considered, and the analysis objects shift from the interactive relations of the actors involved (e.g., firms, countries, local governments, international organizations, and NGOs) at different geographic scales (e.g., global, national, regional, and local) to lead firms' value capture trajectories. In GPN 2.0, lead firms are defined by the percentage size of its market share in a specific production network. To respond to different dynamic competitive environments, lead firms make different strategic decisions (e.g., intra-firm coordination, inter-firm control, inter-firm partnership, and extra-firm bargaining); among such decisions, firm-level value capture trajectories directly influence the spatial output of regional economic development. Thus, the GPN 2.0 analysis framework has clearly overcome the shortcomings of GPN 1.0, which is excessively loose and all inclusive, making its analysis objects more definite. Coe and Yueng (2015) [5] argue that GPN analysis is particularly useful in observing the dynamic and behavior of global and regional networks as determined by the strategies and decision-making activities of global lead firms.
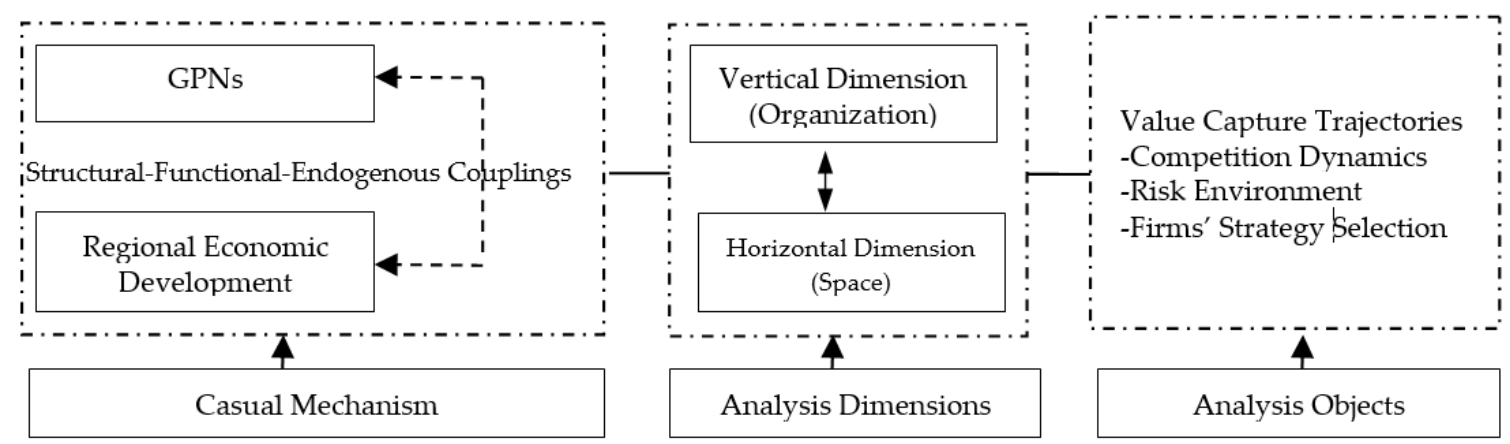

Figure 1. GPN 2.0 analysis framework.

Some scholars have focused on firms' value-add activities. For example, Yang [21] employed firm-centered analysis to analyze the spatial reconstruction patterns and driving force mechanisms of Taiwan-invested cross-border production networks in mainland China. Coe and Lee [22] employed the concepts of 'territorial embeddedness' and 'strategic localization' to analyze the strategic dynamics of Samsung-Tesco after the conglomerate had gained access to the Korean market. The researchers emphasized that foreign-invested firms' localization strategies evolve into a series of dynamic processes over time as the competitive conditions of host countries' markets change. In addition, some scholars have analyzed research on supply relations to investigate the spatial dynamics of local embeddedness and network connections among foreign-invested firms in developed cities in East China; some such scholars have proposed that factors such as foreign-invested firm ownership, the market dynamics of host regions, foreign-invested research and development orientation, firm autonomy, and the degree of technical relevance between foreign-invested firms and local firms influence foreign-invested firms' 
choices of localization strategies and affect regional economic development [23-29]. Although the concept of 'value capture trajectory' in GPN 2.0 has not clearly appeared in the results of any of these studies, similarities can be observed in these studies' analytical content, and the results significantly influenced the selection of quantitative analysis methods in the present study.

Since the introduction of GPN 2.0, some scholars addressed 'strategic coupling' to qualitatively analyze uneven regional development in the context of globalization. However, most scholars analyzed it from national, regional and industrial macro-levels, and few scholars carried out quantitative analysis on lead firms' value capture trajectories. The contribution of this paper is to use valid and reliable data, exploring the value capture trajectories from the micro-level of enterprises, and to find spatial differences of strategic couplings. Moreover, from the evolutionary perspective, this article will put forward some suggestions on regional industrial development for different regions.

\section{Differences between the Economic Growth Trajectories of South and North Jiangsu}

Jiangsu, China, is a developed region situated on the east coast of China. Based on the level of economic development and geographical considerations, Jiangsu is divided into three subregions, namely North, Central, and South Jiangsu. Jiangsu has achieved much in terms of social and economic development since 1978. However, alongside rapid economic growth, the widening gap between the economies of North and South Jiangsu restricts the overall wealth of society in the province. Thus, coordinated socioeconomic development plays a critical role in regional sustainable development [30]. Much empirical research has shown that disparity in the level of economic development from FDI is a key factor of the obvious disparity in the overall degree of economic development within the region $[31,32]$. This section examines the differences in the degrees of economic development and foreign economic development between North and South Jiangsu.

Figure 2 shows the obvious gaps in GDP and GDP per capita between North and South Jiangsu over the preceding 20 years. By examining FDI and export value, we found that South Jiangsu is more economically developed than North Jiangsu. Thus, we deduced that the stable growth of FDI resulted in the higher degree of foreign economic development observed in South Jiangsu. We also found that North Jiangsu has seen rapid growth of FDI over the preceding decade. However, fluctuation in this growth is highly obvious, and the growth of FDI has not led to synchronous growth of export value.

Much empirical research has described that differences in local assets are key reasons for the uneven development between North and South Jiangsu. First, South Jiangsu has obvious location advantages; it is situated at the intersection between the Yangtze River Economic Belt and the Coastal Economic Belt. South Jiangsu is the core region of the Yangtze River Delta, where the manufacturing industry developed early, and the level of development of South Jiangsu has been consistently higher than that of North Jiangsu. Second, Shanghai and Suzhou are the automotive manufacturing base of the Yangtze River Delta. Many automobile manufacturers have been established in these cities, including Shanghai GM, Shanghai Volkswagen, Buick, and JAC Motors. Furthermore, the supporting industry is highly supportive, and logistics costs are low. Competitive and cooperative relations among numerous enterprises have cultivated a healthy local environment for innovation. Finally, the level of economic development in South Jiangsu is evidently higher than that in North Jiangsu, and South Jiangsu has a larger market potential.

South Jiangsu is an early-comer region where people can learn much about the strategic purposes and business conventions of overseas enterprises and the appropriate manners of commercial cooperation with foreign individuals. Through learning and the accumulation of experience, the investment environment of South Jiangsu has improved; thus, the area attracts increasing attention from overseas investors intending to invest directly. Over time, increasing business contacts have facilitated international cooperation, and this has helped South Jiangsu become an influential region in the global economy. Moreover, the risks and uncertainties in South Jiangsu's market and business environment have gradually decreased, and this has reduced overseas investors' operating costs in the area. In addition, long-term development in the manufacturing industry has strengthened the 
supporting industry and has ensured better financial services. For example, financial institutions can now provide better financial services for enterprises. Some venture capital investments and venture capital institutions are also relatively strong in South Jiangsu. Furthermore, the economic development zone in this region was established relatively early, and South Jiangsu has higher administrative capacity. These advantages lead to benefits in policies related to foreign investment and can be referred to as "institutional thickness" in economic geography, which results in path dependence for FDI [32-35].

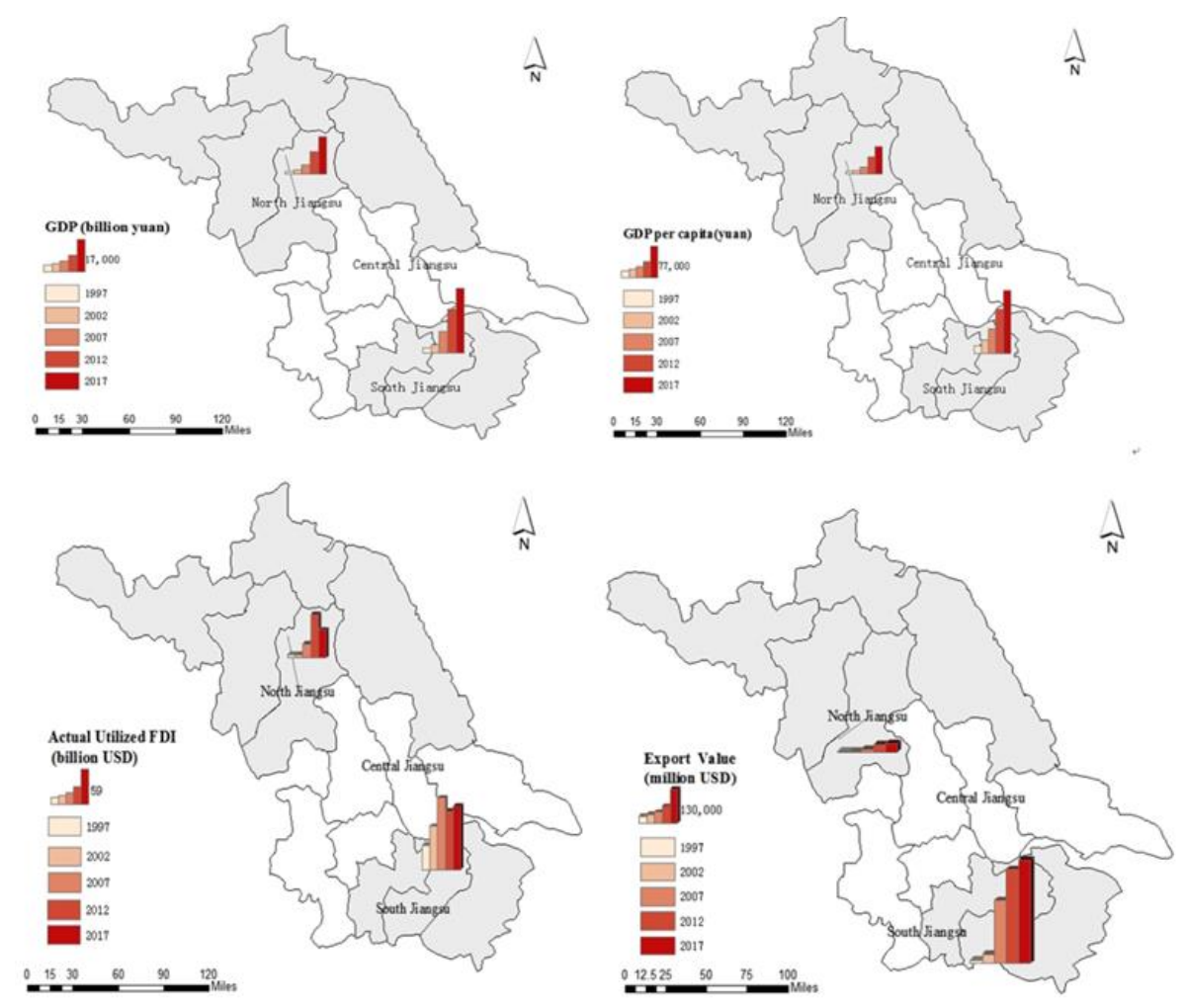

Figure 2. Economic development in South and North Jiangsu in 1998-2018. Sources: Jiangsu Statistical Yearbook 1998, 2003, 2008, 2013 and 2018.

North Jiangsu lacks the aforementioned advantageous local assets of South Jiangsu; thus, the following question should be addressed: How can sustainable economic growth be maintained in Jiangsu, especially North Jiangsu? Does empirical analysis using the strategic coupling framework have implications for coordinated regional development in Jiangsu?

\section{Empirical Analysis and Results}

\subsection{Methodology}

This paper asserts that modes of strategic coupling can be examined by analyzing the value capture trajectories of overseas enterprises in relation to the horizontal (spatial) and vertical (organizational) dimensions. Value capture trajectories refer to the strategic choices made by foreign enterprises when faced with competitive dynamics and risk environment. Automobile industry is characterized by typical producer-driven GPNs; thus, this paper claims that power relationships in GPNs exhibit organizational connection. Moreover, features of buyer-supplier relationships are related to local supplier upgrading; thus, this paper claims that the spatial characteristics of supply relations indicate spatial connection between overseas firms and their host regions.

Most of the KIAFs in Jiangsu are located in Suzhou City and Wuxi City in South Jiangsu and Yancheng City in North Jiangsu. This study selected 62 KIAFs (21 in North Jiangsu and 41 in South Jiangsu); all basic information of the sample firms (firm name, address, phone number, ownership, 
and investment amount) was obtained from Jiangsu Provincial Administration for Industry and Commerce on a pay-to-use basis. The analytical data required for quantization was divided into three types: the position of a firm's power in the GPN, the spatial structures of the trade volume of a firm's upstream and downstream suppliers, and the ownership structures of a firm's upstream suppliers. These three types of data were defined based on detailed face-to-face interviews with and questionnaires issued to firm managers.

The following points should be highlighted: First, the spatial structure of trade volume was used to demonstrate the spatial characteristics of firms' supply relations. The trade volumes of foreign-invested firms and their upstream and downstream suppliers can closely reflect the characteristics of supply relations; however, dialed spatial characteristics of trade volume are inaccessible because they are confidential firm information. Therefore, in this study, the characteristics of the spatial structures of firms' trade volumes were obtained from face-to-face interviews with and through questionnaires issued to foreign-invested firm managers. The sources of upstream and downstream suppliers were categorized the local area, Jiangsu (except the local area), China (except Jiangsu), and the world (except China) and were reflected by the ratio of each source to the total trade volume in quantitative terms. Second, the GPN of the automobile industry is a typical producer-driven network, and thus, organizational characteristics of the GPN's vertical dimension are represented simply by the positions of firms' power within the GPN. Third, the ownership attributes of upstream suppliers directly mirror the strategic selections made by said firms in response to dynamic competitive environments; however, because most firms intend to occupy the local market, the ownership attributes of downstream suppliers were not considered. In the paper, we divided upstream supplier ownership attributes into the following four types: orientation to domestic-invested firms, balance between domestic-invested firms and Korean-invested firms, orientation to Korean-invested firms, and no cooperation with local domestic-invested firms. The present study employed SPSS 22.0 for cluster analysis of the aforementioned three types of data for 62 sample firms to investigate the firm-level value capture trajectories of various firm types in Jiangsu. Comparisons were made between South and North Jiangsu to determine differences between the strategic coupling modes of these two subregions. Furthermore, this study attempted to find implications for economic sustainability in Jiangsu.

\subsection{K-means Cluster Analysis and Empirical Result}

K-means cluster analysis, also known as fast sample clustering, is a commonly used nonhierarchical clustering method $[36,37]$. With the advantages of little memory requirement, a low calculation amount, and rapid processing, K-means cluster analysis is especially suitable for analyzing large samples. In this study, the number of classifications was first determined. For the clustering of observed samples, the clustering variables must be continuous variables. The specific approach is described as follows:

1. According to the specified number of classifications $n$, some observation samples are selected and set to $\{Z 1, Z 2, \ldots Z n\}$, which are the initial centers.

2. The Euclidean distance of each observation sample to the convergence is calculated using Equation (1).

$$
d_{i j}=\left\|x_{i}-z_{j}\right\|=\left[\sum_{k=1}^{m}\left(x_{i k}-x_{j k}\right)^{2}\right]^{\frac{1}{2}}
$$

According to the principle of proximity, each observation sample is attributed to a class, and the central position of each class is then calculated as the new center.

3. The new center is used to reclassify the observation samples, and the center of each class is then recalculated and updated. The updated operation is then repeated until one of the conditions is met- either the maximum change in the distance between the centers of two adjacent iterations is more minor than the multiple of the minimum distance between the initial centers, or the upper 
limit of the number of iterations is reached. When one of these conditions is met, the iteration is halted.

This study conducted K-means cluster analysis of the 62 sample firms according to four variables, namely power relation position in the auto production network, the spatial structure of buyers, the spatial structure of suppliers, and the ownership of downstream suppliers. After five iterations, six clusters were obtained. Compared with the initial cluster center, the final cluster center exhibited some variation among clusters 3, 4, and 6 (Tables 1 and 2). Table 3 shows the results of K-means cluster analysis.

Table 1. Initial cluster centers.

\begin{tabular}{|c|c|c|c|c|c|c|c|c|c|c|}
\hline \multirow[t]{2}{*}{ Cluster } & \multirow{2}{*}{$\begin{array}{l}\text { Position } \\
\text { in GPN }\end{array}$} & \multicolumn{4}{|c|}{$\begin{array}{c}\text { Spatial Structure } \\
\text { of Buyers }\end{array}$} & \multicolumn{4}{|c|}{$\begin{array}{l}\text { Spatial Structure } \\
\text { of Suppliers }\end{array}$} & \multirow[t]{2}{*}{$\begin{array}{l}\text { Supplier } \\
\text { Ownership }\end{array}$} \\
\hline & & Global & China & Jiangsu & Local & Global & China & Jiangsu & Local & \\
\hline Cluster1 & 1 & 0.00 & 0.00 & 0.60 & 0.40 & 0 & 0.05 & 0.00 & 0.95 & 1 \\
\hline Cluster2 & 1 & 0.00 & 0.05 & 0.95 & 0.00 & 0 & 0.00 & 0.00 & 1.00 & 3 \\
\hline Cluster3 & 1 & 0.00 & 0.00 & 0.05 & 0.95 & 1 & 0.00 & 0.00 & 0.00 & 4 \\
\hline Cluster4 & 2 & 1.00 & 0.00 & 0.00 & 0.00 & 0 & 0.00 & 0.00 & 1.00 & 3 \\
\hline Cluster5 & 2 & 1.00 & 0.00 & 0.00 & 0.00 & 1 & 0.00 & 0.00 & 0.00 & 4 \\
\hline Cluster6 & 2 & 1.00 & 0.00 & 0.00 & 0.60 & 1 & 0.00 & 0.00 & 0.00 & 1 \\
\hline
\end{tabular}

Note: In column 2, "1" refers to first-tier suppliers in the auto production network, and "2" refers to low-tier suppliers. In column 12 , " 1 " means that the firm's suppliers are primarily domestic Chinese firms, "2" means that both Korean firms and domestic Chinese firms are involved, " 3 " means that the firm's suppliers are primarily Korean firms, and " 4 " means that the firm has no suppliers in China.

Table 2. Final cluster centers.

\begin{tabular}{ccccccccccc}
\hline Cluster & \multirow{2}{*}{$\begin{array}{c}\text { Position } \\
\text { in GPN }\end{array}$} & \multicolumn{3}{c}{$\begin{array}{c}\text { Spatial Structure } \\
\text { of Buyers }\end{array}$} & \multicolumn{3}{c}{$\begin{array}{c}\text { Spatial Structure } \\
\text { of Suppliers }\end{array}$} & \multicolumn{2}{c}{$\begin{array}{c}\text { Supplier } \\
\text { Ownership }\end{array}$} \\
& & Global & China & Jiangsu & Local & Global & China & Jiangsu & Local & \\
\hline Cluster1 & 1 & 0.01 & 0.18 & 0.34 & 0.50 & 0.04 & 0.02 & 0.00 & 0.94 & 2 \\
Cluster2 & 1 & 0.07 & 0.25 & 0.38 & 0.30 & 0.07 & 0.01 & 0.02 & 0.96 & 3 \\
Cluster3 & 1 & 0.00 & 0.19 & 0.00 & 0.81 & 0.00 & 0.00 & 0.90 & 0.10 & 3 \\
Cluster4 & 2 & 0.19 & 0.00 & 0.00 & 0.81 & 0.00 & 0.00 & 0.00 & 1.00 & 3 \\
Cluster5 & 2 & 0.51 & 0.06 & 0.02 & 0.41 & 0.99 & 0.00 & 0.00 & 0.10 & 4 \\
Cluster6 & 2 & 1.00 & 0.00 & 0.00 & 0.00 & 0.00 & 0.00 & 0.00 & 1.00 & 1 \\
\hline
\end{tabular}

Table 3. Results of K-means cluster analysis.

\begin{tabular}{ccc}
\hline Cluster & Number & Firm Code \\
\hline Cluster0 & 1 & F13. \\
Cluster1 & 8 & F22, F23, F24, F31, F47, F48, F49, F52. \\
Cluster2 & 14 & F10, F11, F12, F33, F34, F38, F39, F40, F43, F44, F54, F58, F61. \\
Cluster3 & 14 & F1, F3, F4, F6, F7, F8, F9, F14, F15, F16, F17, F18, F19, F20. \\
Cluster4 & 10 & F27, F28, F29, F35, F36, F37, F41, F42, F45, F46. \\
Cluster5 & 13 & F2, F5, F21, F25, F30, F32, F50, F51, F53, F56, F57, F59, F60. \\
Cluster6 & 2 & F26, F62. \\
\hline
\end{tabular}

F13 refers to Yanchengyueda, the Kia automotive assembly factory. Because of its special position in the GPN, this cluster is regarded as a separate cluster.

Some obvious characteristics of cluster 1 are described as follows: (1) For the final cluster center, all enterprises in cluster 1 are first-tier suppliers. (2) Buyers are related to three spatial scales, namely China, Jiangsu, and the local area; the local scale accounts for a high proportion of buyers. (3) Regarding the spatial characteristics of suppliers, most suppliers are local enterprises, including both Korean enterprises and domestic Chinese enterprises. This implies that the Korean firms in cluster 1 are relatively unconcerned with whether their suppliers are sourcing from Korea. 
It is thus clear that the sample enterprises had complex supply relation networks and wide market reach. So, this paper argues that the Korean firms in cluster 1 have high ability to adapt to the market. Moreover, the complex ownership structure of their suppliers indicates an open supply relation network. All spatial characteristics in the buyer-supplier relations indicate close connections with the local industry. Eight firms were in cluster 1, namely F22, F23, F24, F31, F47, F48, F49, and F52.

The Korean firms in cluster 2 were all first-tier suppliers in GPNs. Based on the cluster center for the spatial structure of buyers, sales in China accounted for $25 \%$, those in Jiangsu accounted for $38 \%$, those in the local market accounted for $30 \%$. Based on the spatial characteristics of suppliers, most of the enterprises in cluster 2 employed local enterprises as their suppliers; however, most suppliers were related to local Korean firms.

As mentioned, the enterprises in cluster 2 had wide market reach. However, they evidently tended toward cooperation with local Korean firms when choosing suppliers. Thus, this paper argues that these enterprises had low trade dependence on the host region. Cluster 2 contained 14 firms, namely F10, F11, F12, F33, F34, F38, F39, F40, F43, F44, F50, F54, F58, and F61.

The enterprises in cluster 3 are also mainly first-tier suppliers in GPNs. Based on the cluster center of the spatial structure of buyers, local sales accounted for $80 \%$ of all sales. Based on the spatial structure of suppliers, the firms in cluster 3 invariably tended toward cooperation with Korean firms in Jiangsu, as opposed to local firms. Thus, this study concluded that the supply relation network had a low degree of embeddedness. Cluster 3 contained 14 firms, namely F1, F3, F4, F6, F7, F8, F9, F14, F15, F16, F17, F18, F19, and F20.

The enterprises in cluster 4 are mainly low-tier suppliers in GPNs. The firms in this cluster sold their products in the local market. Based on the spatial structure of their suppliers, these firms tended to employ local Korean firms as their suppliers and were located near buyers for timely delivery. Although they were integrated into the local production network via supply relations, they evidently favored Korean suppliers. Thus, this paper asserts that these firms did not exhibit a high degree of embeddedness and therefore contributed little to the development of the local industry. Cluster 4 contained 10 firms, namely F27, F28, F29, F35, F36, F37, F41, F42, F45, and F46.

The enterprises in cluster 5 also mainly low-tier suppliers in GPNs. Based on the cluster center for buyers, some firms in this cluster exported goods overseas, whereas others operated within the local market. Those that operated within the local market invariably imported materials from their home countries and maintained production within the local area. If production costs increased, these firms always relocated to other low-cost regions. Thus, the firms in cluster $5 \mathrm{had}$ a low degree of local embeddedness. Cluster 5 contained 13 firms, namely F2, F5, F21, F25, F30, F32, F50, F51, F53, F56, F57, F59, and F60.

The enterprises in cluster 6 are all low-tier suppliers in GPNs, and all of them exported goods overseas. Their suppliers were distributed throughout the local area, and most were local domestic firms. Thus, by localizing their supply relations, these firms reduced their production costs. Based on this finding, this paper asserts that the firms in cluster 6 had a higher degree of embeddedness than did those in cluster 5. Cluster 6 contained only two firms, namely F26 and F62.

As shown in Figure 3, this study observed the following findings related to the spatial characteristics of various types of Korean firms.

First, the Dongfengyueda-Kia automotive Co., Ltd., auto-assembly plant is located in throughout Yancheng City in North Jiangsu. Because the automotive production network is a typical production-driven network, first-tier suppliers invariably supplied to their assembly plants to meet the demands of "just-in-time" production. Thus, the spatial organization of the automotive industry shapes a unique "auto city".

Second, in North Jiangsu, the 14 firms in cluster 3 were dominant, supplying parts or production materials to Dongfengyueda-Kia automotive Co., Ltd.; these firms invariably employed Korean firms in South Jiangsu as their upstream suppliers. 


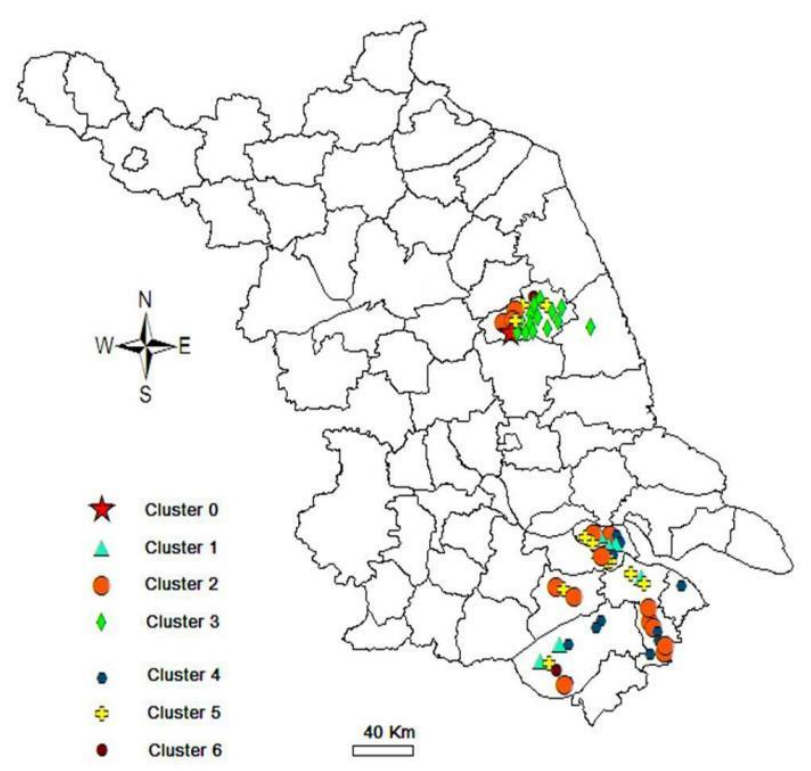

Figure 3. Spatial characteristics of buyer-supplier relations.

Third, three of the firms in cluster 2 were located in North Jiangsu. These firms supplied products to Dongfengyueda-Kia automotive Co., Ltd., and Beijing-Hyundai automotive Co., Ltd., and these firms employed local Korean firms as their upstream suppliers. Another three such firms were in cluster 5; these firms imported parts and production materials from their home countries, maintained production in the local area, and subsequently exported their products back to their home countries.

Finally, the structure of clusters in South Jiangsu was complex, including cluster 1 (8 firms), cluster 4 (10 firms), cluster 5 (10 firms), and cluster 6 (2 firms). Clusters 1, 4, and 6 were only in South Jiangsu. The firms in cluster 1 exhibited a complex and open supply relation network, which implies a high degree of embeddedness. Cluster 4 contained low-tier suppliers; although the enterprises in cluster 4 had simple supply relations, they had strong intentions to cooperate with domestic enterprises, and they enhanced the competitiveness of their products through the localization of supply relations. The enterprises in cluster 6 had no contact with local businesses and thus faced considerable pressure in the form of production costs.

\section{Discussion}

\subsection{Firm-Level Value Capture Trajectories in North and South Jiangsu}

From the above analysis, we find that there are obvious differences between North and South Jiangsu in the spatial agglomeration characteristics of firms with different ownership attributes. According to the literature in Section 2.2, the GPN 2.0 analysis framework emphasizes quantitative analysis from two dimensions of organizational and spatial dimensions. The spatial pattern of supply relationship network not only reflects the network relationship at the organizational level, but also reflects the spatial characteristics of GPNs' locational selection. Below, we will discuss the value capture trajectories of lead firms (defined automotive assembly plant and first-tier suppliers in this paper).

\subsubsection{Value Capture Trajectories in North Jiangsu}

In North Jiangsu, the firms in the local production network mainly include the Yueda-Kia automotive assembly plant, Korean-owned first-tier suppliers and a small number of small-size firms as second- and third-tier suppliers. As the lead firm in the GPN, KIA Motor plays a dominate role, capturing a number of Korean-owned firms and locks the interests in Korean parts through inter-firm cooperation. From the perspective of space, Korean-invested leading firms hardly have 
supply relationships with local domestic firms, but have supply relationships with South Jiangsu and other regions with a mature automobile industry.

The organizational and spatial characteristics of supply relationship networks show the value capture strategies of Korean-invested enterprises in North Jiangsu as follows: (1) In accordance with the joint venture agreement, Korean investors usually request absolute control inside the joint venture group. Inside the assembly plants, the key departments including the purchasing department, marketing department, and development planning department, are also controlled by the Korean investors. The Chinese party is responsible for only production department. The design rights of whole vehicles and parts belong to the Korean party, and thus, the Korean party controls quality authentication, design modification and related expenses, the selection of supporting enterprises with respect to parts, the price of imported parts, and the purchasing and price of imported equipment. (2) In consideration of long-term operation and brand image, the Korean party chooses the Korean enterprises with which to engage in long-term cooperative relationships to minimize risk arising from supplier uncertainty. (3) The Korean party can enhance its value through the closed support circle. For example, all purchased parts at Dongfengyueda-Kia must be tested at the Test Center of Shanghai Mobis Automotive Parts Co., Ltd. Therefore, as Hyundai Mobis, related to Korean Hyundai Kia, achieves great profit in China, the Hyundai Kia Group may also profit. (4) Korean enterprises have a strong position in Yancheng and strong bargaining power against local actors (e.g., the government, nongovernmental organizations, and individuals). Single enterprise ownership and the aforementioned closed support circle suggest that the degree of embeddedness of Dongfengyueda-Kia in the local production network is not high.

\subsubsection{Value Capture Trajectories in South Jiangsu}

In South Jiangsu, the firms in local production network include multi-directivity first-tier suppliers, single-directivity first-tier suppliers, and three types of low-tier suppliers, which shape the complex and open supply relationship networks. Below, combined with interview information we further analyze lead firms' value capture trajectories in South Jiangsu.

\section{(1) Multi-directivity first-tier suppliers}

This category of firms takes the Chinese market exploitation as the enterprise strategic emphasis, with the requirement of production localization. This type of firms has a clear understanding of the local institutional background and the future changing trend of the local industry. These firms take the spatial expansion of commodity chain as the way to solve the future uncertainties arising from the change of institutions. Therefore, these enterprises emphasize the supporting condition of the investment place and actively establish the relations with the domestic firms. In early period, their products were only supplied to Beijing-Hyundai in Beijing and Dongfengyueda-KIA in Yancheng. However, drove by the strong willing of market expansion, they actively insert into the automobile GPNs of other countries in China. However, there are some difficulties for them to adapt to the conventions in operation system of Chinese automobile industry. For the selection of upstream suppliers, they value the cooperation with the local domestic enterprises. Both the open production network tropism and high localization degree of parts and accessories implies a relatively high-level embeddedness; but the dominant directivity of Korean downstream suppliers shows that their parent companies play very important role in making the spatial decision of the future investment.

\section{(2) Single-directivity first-tier supplier}

This category of enterprises has two types as follows: one refers to first-tier suppliers captured only by Hyundai-Kia automotive group. The other is the type of enterprises which products flow to non-Korean cars. For the degree of the dependence on local economy, two types of enterprises have some differences. 
The former supplies their products to Korean assembly plant. As key parts and components suppliers for Korean car, they have weak intention to develop local market. For the choice of upstream suppliers, this type of enterprises always vales price and quality, and pays little attention to whether the suppliers sourcing from Korea. Thus, there are many local domestic companies become their suppliers. So, this type of enterprises pays attention to supporting conditions in the host region or locality. Moreover, types of ownerships for enterprises in supply chain are multiple, which implies a relatively higher level of local dependence.

The parent companies of this category of firms are global suppliers of non-Korean automobile factories, and the extension of the GPN of auto giants in China affects the global development strategies of TNCs. Regarding the selection of investment regions, this category of firms wishes to be near Shanghai. Specifically, these firms value the characteristics of an export-oriented economy. The global purchasing strategies of auto giants require this category of enterprises to engage in deep localization to reduce production costs. Thus, regarding the selection of upstream suppliers, these firms pay little attention to whether enterprises having background in Korean investment. By contrast, when cost is considered, these enterprises are more inclined toward domestic enterprises. In the initial period of development, these enterprises regularly obtained production orders while being reliant on the relationships between their parent companies and auto manufacturers. However, as these firms become increasingly familiar with the local market, their willingness to expand the Chinese market grew. The major economic development zones and high-tech industrial zones in Suzhou and Wuxi are the primary agglomeration regions; in particular, Zhangjiagang and Kunshan have favorable logistics conditions and industrial supporting conditions and thus have become the centralized distribution regions. The open support circle and supply relations involving many domestic enterprises imply a high degree of embeddedness for this category of enterprises.

\subsection{Strategic Coupling Modes in North and South Jiangsu}

This study found that although the firm-level value capture trajectories of the firms in North Jiangsu and those in South Jiangsu are similar, obvious differences can be observed between the two regions, and these differences imply variation between the strategic coupling modes of the two regions.

In North Jiangsu, the Kia Motor Group values generic regional assets and policy superiority and has shaped the automotive manufacturing industry cluster in Yancheng through territorial embeddedness. Because of uncertainty in the local investment environment, the KIAFs analyzed in this study seldom cooperate with local domestic firms; in addition, the KIAFs strictly reserve benefits for themselves through a hierarchy of power relations in the GPN and internal company control strategies. Clearly, the KIAFs are insufficiently motivated to cooperate with local firms; such cooperation would be unfavorable for regional innovation and upgrading. Thus, this paper argues that North Jiangsu is currently at the stage of "structural coupling." North Jiangsu is connected to the GPN of Kia Motors passively and relies heavily on external forces. As local assets evolve, decoupling is likely to occur.

By contrast, South Jiangsu is at the stage of "functional coupling". The KIAFs in this region place higher value on aspects such as local market potential, supporting industry conditions, and an environment conducive for the long-term development of foreign investment. These KIAFs have been captured by more than one GPN outside South Jiangsu. To overcome the tightening policies for auto manufacturing in South Jiangsu, these firms usually choose to cooperate with local domestic-invested firms to minimize costs; the technology of local domestic-invested firms is not considerably different from that of these KIAFs, which can also actively develop relations with GPNs outside the region.

Generally, in the initial stage of economic development, industrial policies have obvious effects; by contrast, at the more mature stage of economic development, such policies are usually ineffective [38]. At present, foreign investment policies remain at a level where they attempt to satisfy the demands of foreign-invested firms in terms of general production elements in North Jiangsu. The establishment of such low-level structural coupling leads to an insufficient driving force for strategic coupling among TNCs and local firms. As stated by Grunsven and Hutchinson [17], “Blindly improving a 
region's adaptability to GPNs will only retard the effective strategic bonding between regional economy and MNCs and further destroy the development potential of the region." In other words, industrial policies should be forward-thinking and in line with the characteristics of industrial development in its current state [39]. Presently, North Jiangsu should strive to play the role that local governments should play in regional development and should actively create a local institutional environment that facilitates the economic development of foreign investment. In addition, North Jiangsu should take full advantage of the automotive industrial clusters in the coastal areas of Jiangsu, boost the spatial gathering of TNCs sourcing from multiple countries, shift the unequal power relations between KIAFs and local governments, and break up KIAFs' closed supply relation networks [40]. The region should also seek to enhance local firms' intrinsic innovation impetus, minimize the technological gaps between domestic- and foreign-invested firms, facilitate beneficial competition and cooperative relationships between TNCs and local firms, and prepare for functional coupling. South Jiangsu should actively facilitate the transition from functional coupling to endogenous coupling. In South Jiangsu, the economic development of foreign investment is at a relatively mature stage; thus, excessive policy intervention would be harmful to sustainable industrial development. The global automotive industry is currently undergoing a profound revolution; Internet-based companies are increasingly reaching out to the automotive industry, and auto products are shifting from automobiles to large mobile intelligent terminals [41,42]. Given these circumstances, local governments should actively urge cost-sensitive firms to become de-embedded to reserve space and resources for related firms with technological superiority and development potential; in addition, they should develop automotive industrial innovation centers with independent research and development abilities that are subject to specified standards, utilize correlations among competitive industrial technologies to equip the automotive industry with comparative global advantages, take advantage of opportunities such as the Belt and Road Initiative, actively promote investment overseas, and establish GPNs outside the region to enhance value and boost regional economic development.

\section{Conclusions and Implications}

Based on the study results of Coe, Yueng, Dicken, Henderson, and their colleagues, who have been the main contributors to the theoretical GPN framework, the present study focused on the evolution and differences between the various stages of the framework. GPN 2.0 differs from GPN 1.0 in its explanation of the regional development mechanism and study framework. GPN 2.0 holds that strategic coupling is dynamic and undergoes the coupling-decoupling-recoupling process, and that only through the realization of strategic coupling from a low to high level (i.e., structural coupling-functional coupling-endogenous coupling) can a regional economy thrive. The GPN 2.0 analysis framework has two basic dimensions, namely the vertical (i.e., organizational) and horizontal (i.e., spatial) dimensions; the cross-influence of both dimensions is the driving mechanism of regional development. In addition, GPN 2.0 focuses its analysis on firm-level value capture trajectories as opposed to interactive relationships among scalar and diversified actors.

This study drew on the theories and concepts known as strategic coupling and value capture trajectories in GPN 2.0, and through the GPN 2.0 analysis framework, this study explored the firm-level value capture trajectories of KIAFs in Jiangsu, China, and then analyzed the differences between the strategic coupling modes of North and South Jiangsu: which two economic development poles in Jiangsu. This study found that different types of KIAFs employ different development strategies in dynamic competitive environments. Through comparing North and South Jiangsu, this study found obvious similarities within these regions but obvious differences between them. Although North and South Jiangsu share the same top-down strategic coupling mode initiated by the government, they are currently at different strategic coupling levels and stages. North Jiangsu is at the stage of "structural coupling", whereas South Jiangsu is at the relatively mature stage of "functional coupling." Thus, this paper argues that spatial settings such as regional assets and autonomy are key factors influencing the uneven economic development outcomes in these regions. To achieve coordinated 
economic growth, these regions must break down low-level strategic coupling and transition to a higher level. Moreover, regional economic growth should be driven more by endogenous growth than by external forces.

With the long-term development of foreign capital economy, South Jiangsu already has the advantage of special assets and high autonomy. Automobile technology is in the period of great change in a hundred years, the trend of intelligence, automation, sharing and electrification is more obvious [43]. Thus, the government should adjust the industrial policy, make some cost-sensitive enterprises actively 'decoupling' for the development of new technology space. In a market economy, the withdrawal of less competitive firms is an important part of the metabolic process of the economic system, which is conducive to optimizing the allocation of resources [44]. In addition, domestics leading firms should be encouraged to establish GPNs, plan value-added activities on a global scale.

In underdeveloped North Jiangsu, the development of foreign capital economy started later than that in South Jiangsu, and the degree of industrial agglomeration was low. Whether the advantages of regional assets or autonomy are relatively low, but blindly improving the adaptation of the region to GPNs will only block the effective strategic connection between the regional economy and TNCs, and then destroy the potential of regional development. Therefore, North Jiangsu should fully benefit the advantages of Jiangsu coastal automobile industry cluster, further promote the local agglomeration of multi-sourcing TNCs, break the closed supply relationship network formed by Korean-invested enterprises, and then improve the bargaining power of the region in GPNs. In addition, the government should optimize and improve the local institutional and cultural environment, strengthen vocational skills training, improve the irreplaceability of regional assets, and accelerate the transformation from structural coupling to functional coupling.

In addition, compared with GPN 1.0, GPN 2.0 more clearly demonstrates the dynamic characteristics of regional development in the context of globalization. Thinking over the formulation of dynamic regional industry policies based on the stage characteristics of strategic coupling has merits that are worthy of consideration by regional industrial policy makers. Moreover, many GPN-1.0-based studies have independently developed analyses from multiple perspectives such as synergy among local assets, economic embeddedness, and social embeddedness, but this analytical framework is too loose. GPN 2.0 combines the organizational and spatial dimensions into a similar study framework and makes the analysis relevant to the characteristics of global-local connections, which are manifested in the value capture trajectories of foreign-invested firms; thus, GPN 2.0 exhibits more definite guiding significance for local firms and industrial upgrading. This empirical study also discovered that some indicators of the competitive dynamics encountered by firms overlap or are ambiguous and thus highly difficult to quantify; in addition, the causality between these competition dynamics and firms' strategic selections is difficult to simulate using a mathematical model; thus, qualitative analysis dominates in such cases. Consequently, the problem that quantitative analysis cannot be conducted in GPN 1.0 remains unsolved, and the theoretical framework requires further improvement.

Author Contributions: Conceptualization, H.X.; formal analysis, H.X. and W.-L.H.; investigation, W.-L.H.; methodology, H.X. and W.-L.H.; software, Y.-C.L.; visualization, Y.-C.L. and S.-W.L.; writing-original draft, H.X.; writing-review and editing, W.-L.H., Y.-C.L. and T.-Y.C. All authors have read and agreed to the published version of the manuscript.

Funding: This research was funded by 2020 Major Project about the Philosophy and Social Sciences of Higher education in Jiangsu Province, China. (Grant Number: 2020SJZDA043).

Acknowledgments: We are grateful to the editor and anonymous reference for their comments. In addition, we would like to thank Yilin Li who studies in Huaiyin Normal University for her great contribution to the typesetting and proofreading of the article.

Conflicts of Interest: The authors declare no conflict of interest. 


\section{References}

1. Yueng, H.W.-C.; Coe, N.M. Towards a dynamic theory of global production networks. Econ. Geogr. 2015, 91, 29-58. [CrossRef]

2. Dicken, P.; Kelly, P.; Olds, K.; Yeung, H.W.-C. Chains and networks, territories and scales: Towards a relational framework for analyzing the global economy. Glob. Netw. 2001, 1, 89-112. [CrossRef]

3. Henderson, J.; Dicken, P.; Hess, M.; Coe, N.; Yeung, H.W.-C. Global production networks and the analysis of economic development. Rev. Int. Political Econ. 2002, 9, 436-464. [CrossRef]

4. Coe, N.M.; Hess, M.; Yeung, H.W.; Dicken, P.; Henderson, J. 'Globalizing'regional development: A global production networks perspective. Trans. Inst. Br. Geogr. 2004, 29, 468-484. [CrossRef]

5. Coe, N.M.; Yeung, H.W.-C. Global Production Networks: Theorizing Economic Development in an Interconnected World; Oxford University Press: Oxford, UK, 2015.

6. Sunley, P. Relational economic geography: A partial understanding or a new paradigm. Econ. Geogr. 2008, 84, 1-26. [CrossRef]

7. Coe, N.M.; Yeung, H.W.-C. Global Production Networks; Oxford University Press: Oxford, UK, 2015; pp. $178-188$.

8. Yeung, G. The operation of global production networks (gpns) 2.0 and methodological constraints. Geoforum 2016, 75, 265-269.

9. Xu, H.; Hsu, W.-L.; Meen, T.-H.; Zhu, J.H. Can higher education, economic growth and innovation ability improve each other? Sustainability 2020, 12, 2515. [CrossRef]

10. Mackinnon, D.; Cumbers, A. An introduction to economic geography: Uneven development and place. N. J. 2007, 8, 59-81.

11. Coe, N.W.; Dicken, P.; Hess, M. Global production networks realizing the potential. Econ. Geogr. 2008, 8, 271-295. [CrossRef]

12. Miao, C.H.; H., W.Y.; Lv, L.C. New Economic Geography; Science Press: Beijing, China, 2011; pp. 78-79.

13. Liu, Y. Theoretical thread and problems of strategic coupling. Geogr. Res. 2018, 37, 1421-1434.

14. Nilsen, T. Global production networks and strategic coupling in value chains entering peripheral regions. Extr. Ind. Soc. 2019, 6, 815-822. [CrossRef]

15. Wang, Y.; Jun, H.; Jian, Z. From gpn 1.0 to 2.0: Review and progress in the study of the global production networks. Geogr. Geo Inf. Sci. 2017, 33, 87-93.

16. Yueng, H.W.-C. Global production network, value capture trajectories and regional development. Trop. Geogr. 2017, 37, 628 .

17. Grunsven, L.; Hutchinson, F.E. The evolution of the electronics industry in johor (malaysia): Strategic coupling, adaptiveness, adaptation, and the role of agency. Geoforum 2016, 74, 74-87. [CrossRef]

18. Sanz-Ibáñez, C.; Clavé, S.A. Strategic coupling evolution and destination upgrading. Ann. Tour. Res. 2016, $56,1-15$.

19. He, C. Global production network and the development in the eastern area. China Ind. Econ. 2017, 11, 50-57.

20. Neilson, J.; Dwiartama, A.; Fold, N.; Permadi, D. Resource-based industrial policy in an era of global production networks: Strategic coupling in the indonesian cocoa sector. World Dev. 2020, 135, 105045. [CrossRef]

21. Nilson, J.; Pritchard, B.; Fold, N.; Pritchard, B. Lead firms in cocoa-chocolate global production network: An assessment of the deductive capabilities of gpn 2.0. Econ. Geogr. 2018, 94, 400-424. [CrossRef]

22. Yang, C. Restructuring the cross-borber production networks of taiwanese investment in china: Relocation of personal computer firms from pearl river delta to yangtze river delta. Delta. Acta Geogr. Sin. 2011, 66, 1343-1354.

23. Coe, N.M.; Lee, Y.S. 'We've learnt how to be local': The deepening territorial embeddedness of samsung-tesco in south korea. J. Econ. Geogr. 2013, 13, 327-356. [CrossRef]

24. Wei, Y.D.; Liao, F.F. The embeddedness of transnational corporations in chinese cities: Strategic coupling in global production networks? Habitat Int. 2013, 40, 82-90. [CrossRef]

25. Luo, Q.; He, C.F.; Guo, Q. Interaction between the spatial dynamics of foreign direct investment and domestic industrial change in chinese prefecture-level cities. Prog. Geogr. 2016, 35, 1369-1380.

26. Wei, Y.D. Network linkages and local embeddedness of foreign ventures in china: The case of suzhou municipality. Reg. Stud. J. Reg. Stud. Assoc. 2015, 49, 287-299. [CrossRef] 
27. Wei, Y.D.; Zhou, Y.; Sun, Y.; Lin, G.C. Production and r\&d networks of foreign ventures in china: Implications for technological dynamism and regional development. Appl. Geogr. 2012, 32, 106-118.

28. Ferdows, K. Relating the firm's global production network to its strategy. In International Operations Networks; Springer: Berlin/Heidelberg, Germany, 2004; pp. 1-11.

29. Drahokoupil, J.; McCaleb, A.; Pawlicki, P.; Szunomár, Á. Huawei in europe: Strategic integration of local capabilities in a global production network. In Chinese Investment in Europe:Corporate Strategies and Labor Relations; European Trade Union Institute: Brussels, Belgium, 2017; pp. 59-65.

30. Bing-qing, C.H.E.; Chuan-geng, Z.H.U.; Zhao-yi, M.E.N.G.; Yan, D.U.; Zheng-ping, S.H.E.N. The process, structure and mechanisms of coordinated development between economy and society in jiangsu. Geogr. Res. 2012, 13, 797-803.

31. Ou, X.J. Analysis on the differences on regional development of jiangsu province. Areal Res. Dev. 2006, 25, 18-27.

32. Wang, W. A comparison of the impact of fdi and domestic capital on economic development in jiangsu province. Jiangsu Stat. 2003, 1, 19-20.

33. Kent, A. Through thick or thin? The performance and operation of firms and the institutional thickness model. Space Polity 2014, 18, 269-284. [CrossRef]

34. Beer, A.; Lester, L. Institutional thickness and institutional effectiveness: Developing regional indices for policy and practice in australia. Reg. Stud. Reg. Sci. 2015, 2, 205-228. [CrossRef]

35. Zhu, H.Y.; Wang, J.C. The form and mechanism of firms delocalization in the global production network. Sci. Geogr. Sin. 2014, 87, 416-426.

36. Zhang, G.; Li, Y.; Deng, X. K-means clustering-based electrical equipment identification for smart building application. Information 2020, 11, 27. [CrossRef]

37. Chen, G.; Liu, Y.; Ge, Z. K-means bayes algorithm for imbalanced fault classification and big data application. J. Process. Control. 2019, 81, 54-64. [CrossRef]

38. Qi, Y.D.; Zhang, R.Z. A review of the research on the implementing effect of overseas industrial policies. Econ. Inf. 2017, 5, 142-150.

39. Landesmann, M.A.; Stöllinger, R. Structural change, trade and global production networks: An 'appropriate industrial policy' for peripheral and catching-up economies. Struct. Change Econ. Dyn. 2018, 48, 73-87. [CrossRef]

40. Xu, H.Y. Strategic Coupling between Global Production Network and Regional Development; Nanjing University Press: Nanjing, China, 2013; pp. 32-34.

41. $\mathrm{Xu}, \mathrm{J} . \mathrm{W}$. Transformation, upgrading and restructuring of automobile industry in central plains economic zone. Jiangxi Soc. Sci. 2017, 2, 75-82.

42. Zhang, Z.D.; He, W.Y. Cluster spillover between finance and automobile industry in the yangtze river economic belt: Integration or extrusion. Guizhou Soc. Sci. 2017, 4, 125-130.

43. Xu, N.; Li, X.; LI, W. The spatial pattern and underlying factors of exited automobile ventures in China. Geogr. Res. 2020. in Press (In Chinese)

44. Pérez, S.E.; Llopis, A.S.; Llopis, J.A.S. The determinants of survival of spanish manufacturing firms. Rev. Ind. Organ. 2004, 25, 251-273. [CrossRef]

(C) 2020 by the authors. Licensee MDPI, Basel, Switzerland. This article is an open access article distributed under the terms and conditions of the Creative Commons Attribution (CC BY) license (http://creativecommons.org/licenses/by/4.0/). 